\title{
A Universal Method for Enhancing the Structural Stability of Ni-rich Cathodes via Synergistic Effect of Dual-element Co- substitution
}

Feng Wu, ${ }^{a, b} \mathrm{Na} \mathrm{Liu},{ }^{a, b}$ Lai Chen, ${ }^{*},{ }^{a}{ }^{b}$ Ning Li, ${ }^{a}{ }^{b}$ Yun Lu, ${ }^{a, b}$ Duanyun Cao, ${ }^{a, b}$ Mingzhe Xu, ${ }^{a, b}$ Zirun Wang, ${ }^{a, b}$ Yuefeng Su ${ }^{*}, a, b$

${ }^{a}$ School of Materials Science and Engineering, Beijing Institute of Technology, Beijing Key Laboratory of Environmental Science and Engineering, Beijing, 100081, P. R. China

${ }^{b}$ Beijing Institute of Technology Chongqing Innovation Center, Chongqing, 401120, P. R. China

KEYWORDS: Lithium-ion battery; Nickel-rich layered cathode; Surface reconstructed structure; Phase transformation propagation; Co-substitution. 

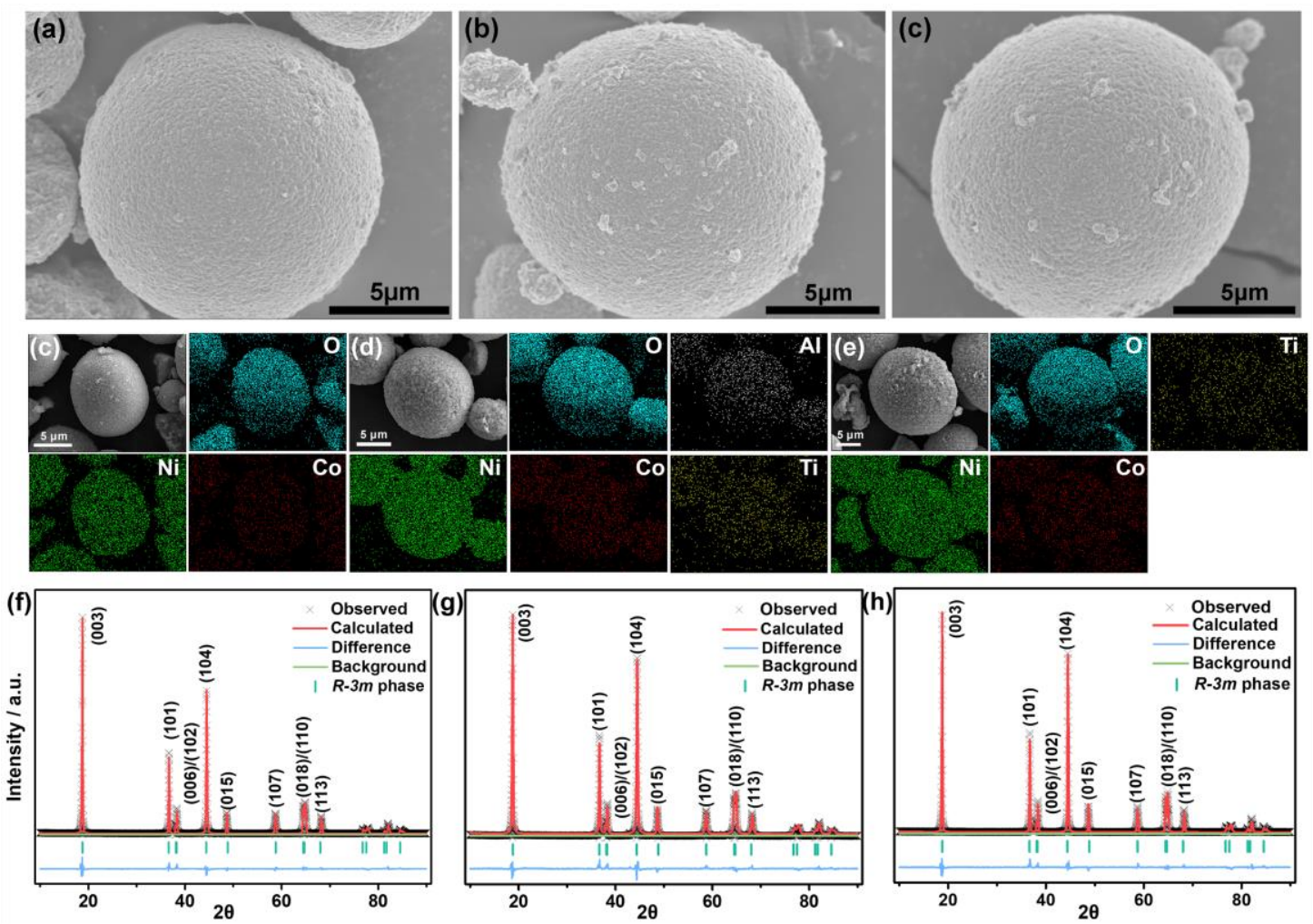

Figure S1 SEM images and EDS elemental maps of (a,c) LNCO, (b,d) LNCTAO and (c,e) LNCTO. The XRD Rietveld refinement plots of (f) LNCO, (g) LNCTAO and (h) LNCTO samples. 
Table S1. Element Composition of the LNCO, LNCTAO and LNCTO by ICP-AES.

\begin{tabular}{cccccccccc}
\hline TM/[Ni+Co] & \multicolumn{2}{c}{ LNCO } & \multicolumn{4}{c}{ LNCTAO } & \multicolumn{3}{c}{ LNCTO } \\
\cline { 2 - 10 } Mol \% & $\mathrm{Ni}$ & $\mathrm{Co}$ & $\mathrm{Ni}$ & $\mathrm{Co}$ & $\mathrm{Ti}$ & $\mathrm{Al}$ & $\mathrm{Ni}$ & $\mathrm{Co}$ & $\mathrm{Ti}$ \\
\hline Calculated & 92.0 & 8.0 & 90.8 & 7.9 & 1.0 & 0.3 & 91.1 & 7.9 & 1.0 \\
Measured & 92.2 & 7.8 & 90.6 & 8.0 & 1.1 & 0.3 & 91.3 & 7.8 & 0.9 \\
\hline
\end{tabular}


Table S2 Summary of R factors and lattice parameters for all the LNCO, LNCTAO and LNCTO.

\begin{tabular}{cccccccc}
\hline Sample & $\mathrm{a}(\AA)$ & $\mathrm{c}(\AA)$ & $\mathrm{V}\left(\AA^{3}\right)$ & $\mathrm{I}_{(003) / \mathrm{I}(104)}$ & $\mathrm{Rwp} / \%$ & $\mathrm{Rp} / \%$ & Ni in Li site / \% \\
\hline LNCO & $2.8727(8)$ & $14.1930(4)$ & 101.441 & 1.48 & 7.67 & 5.60 & 2.38 \\
LNCTAO & $2.8727(6)$ & $14.1990(1)$ & 101.482 & 1.26 & 8.71 & 6.49 & 3.20 \\
LNCTO & $2.8727(3)$ & $14.1993(8)$ & 101.483 & 1.20 & 5.92 & 6.40 & 3.08 \\
\hline
\end{tabular}



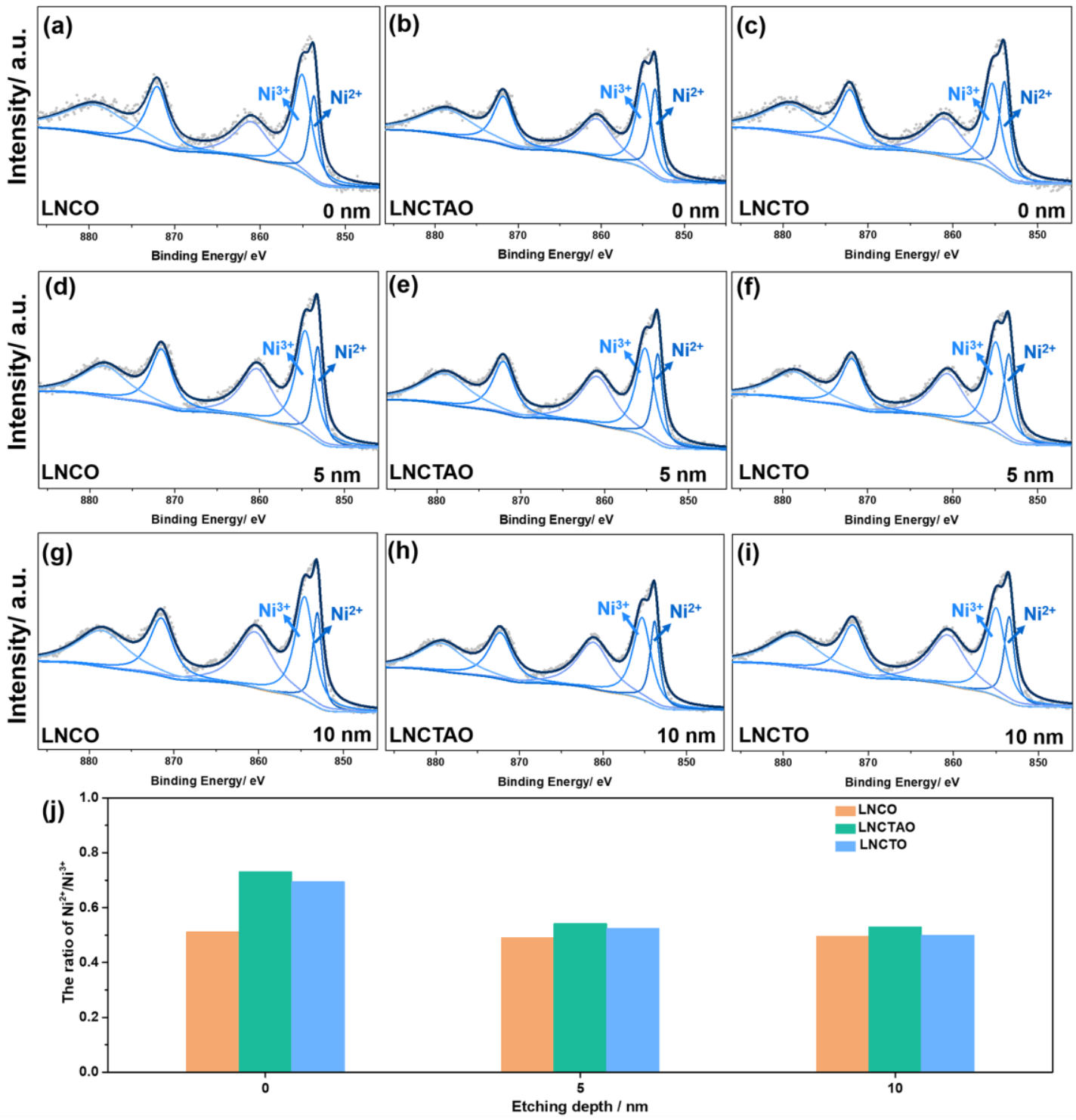

Figure S2 XPS profiles of Ni $2 \mathrm{p}_{3 / 2}$ as a function of etched depth for LNCO, LNCTAO and LNCTO at etched depth of (a-c) $0 \mathrm{~nm}$, (d-f) $5 \mathrm{~nm},(\mathrm{~g}-\mathrm{i}) 10 \mathrm{~nm}$, (j) the ratio of $\mathrm{Ni}^{2+} / \mathrm{Ni}^{3+}$ in different etching depth. 

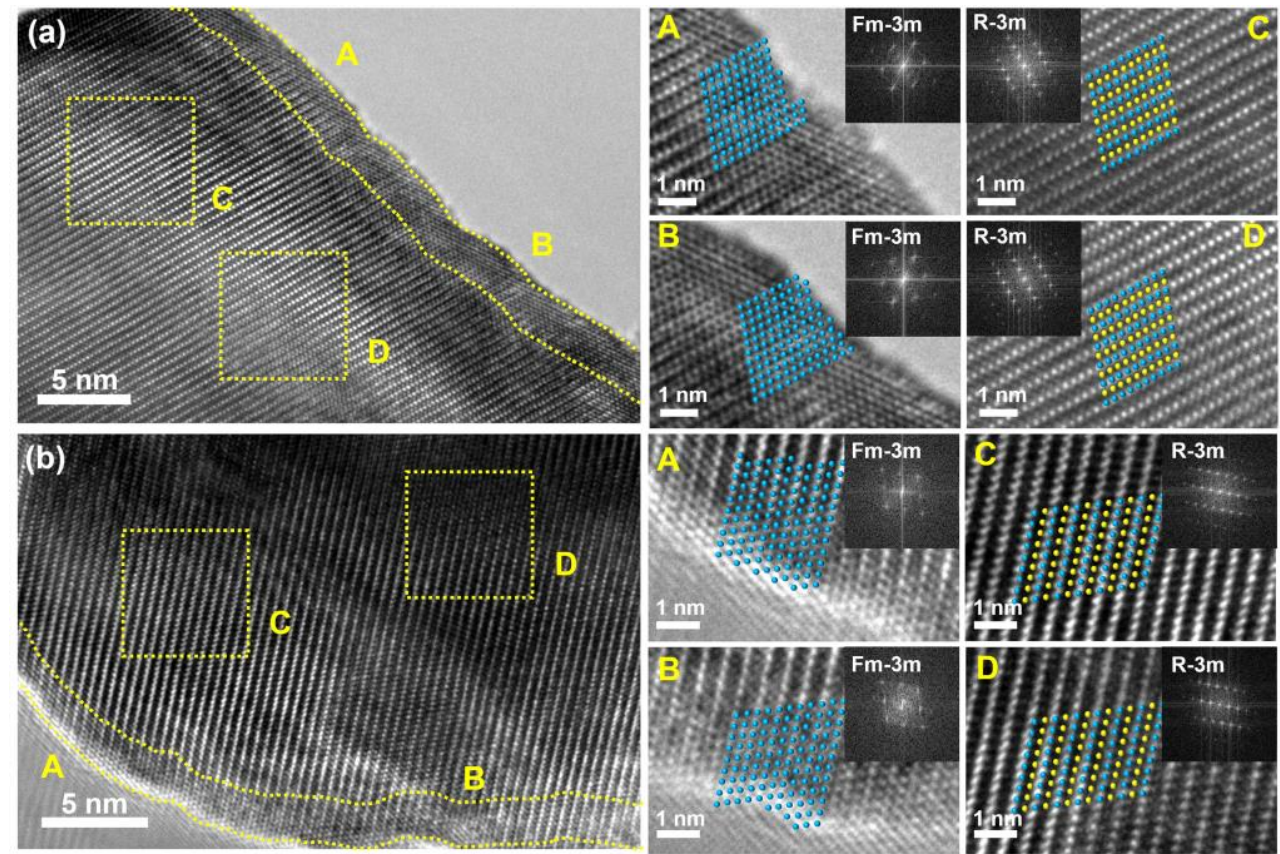

Figure S3 TEM images of the LNCTAO (a-b) in more sections. The corresponding Highmagnification TEM images and FFT images of the marked regions (marked by yellow dash lines) are shown at the right, respectively. 

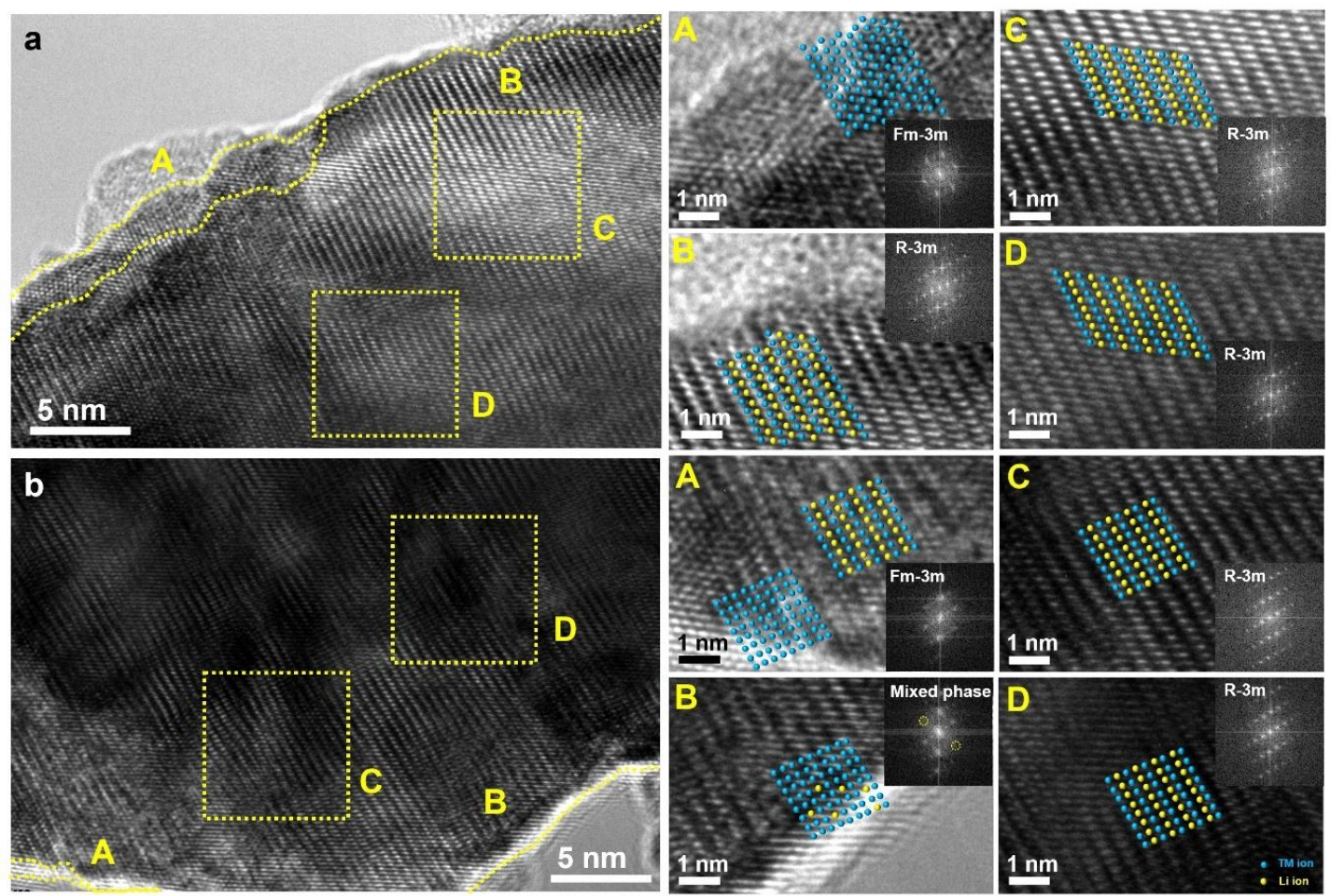

Figure S4 TEM images of the LNCTO (a-b) in more sections. The corresponding Highmagnification TEM images and FFT images of the marked regions (marked by yellow dash lines) are shown at the right, respectively. 
(a)

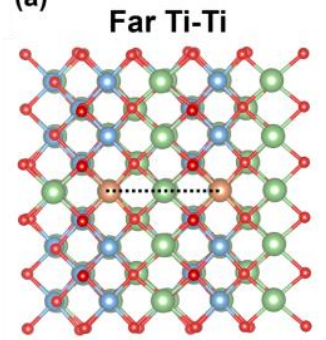

$5.7560 \AA$ (b)

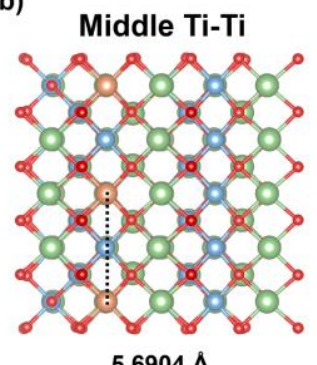

(c)

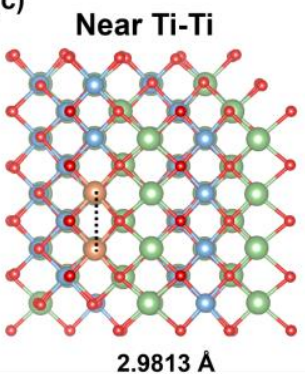

(d)

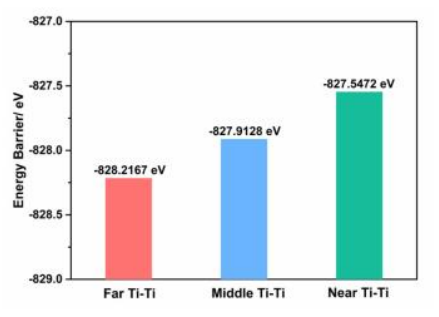

Figure S5 Schematic illustration of three types of Ti doping configurations and the corresponding energy barrier, from left to right: far Ti-Ti, middle Ti-Ti and near Ti-Ti. 
(a)

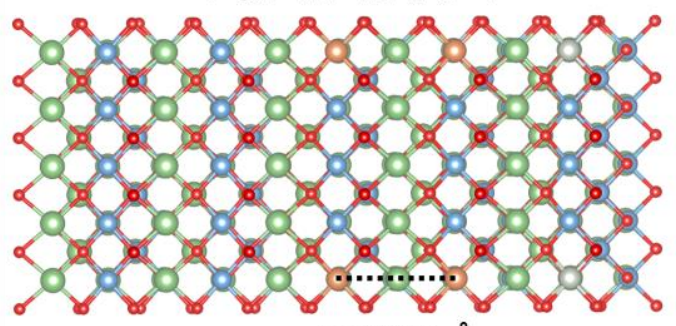

(b) Middle Ti-Ti-A

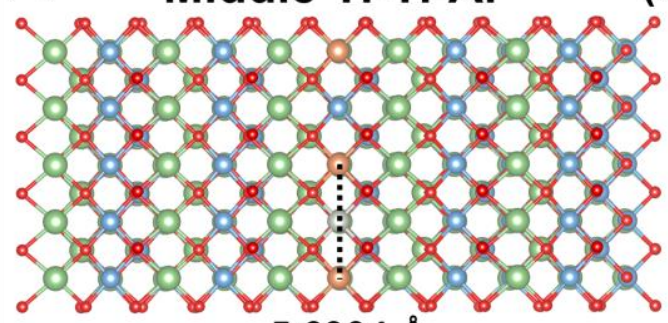

(c) Near Ti-Ti-Al

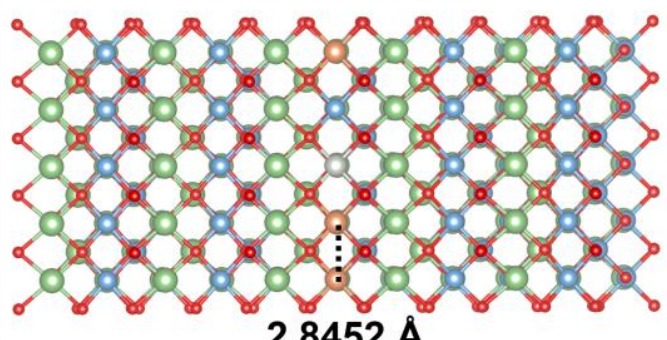
$2.8452 \AA$
Far Ti-Ti-Al-2

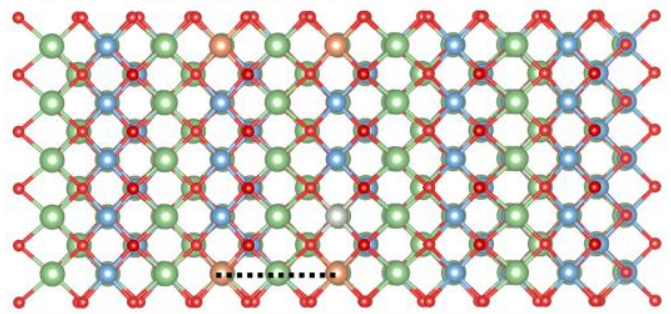

(d)

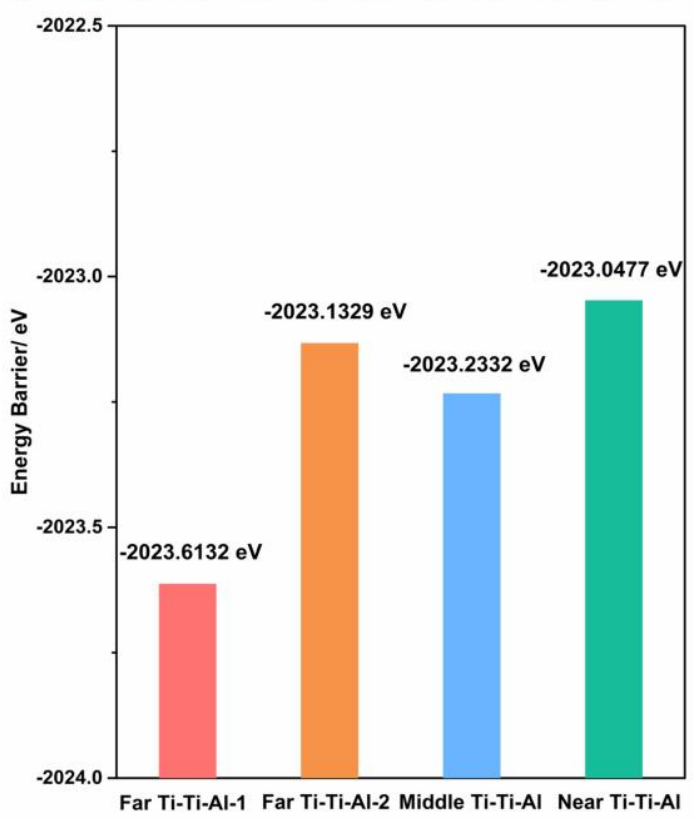

Figure S6 Schematic illustration of four types of $\mathrm{Ti}$ and $\mathrm{Al}$ doping configurations and the corresponding energy barrier, from left to right: far Ti-Ti-Al-1, far Ti-Ti-Al-2, middle Ti-Ti-Al and near Ti-Ti-Al. 

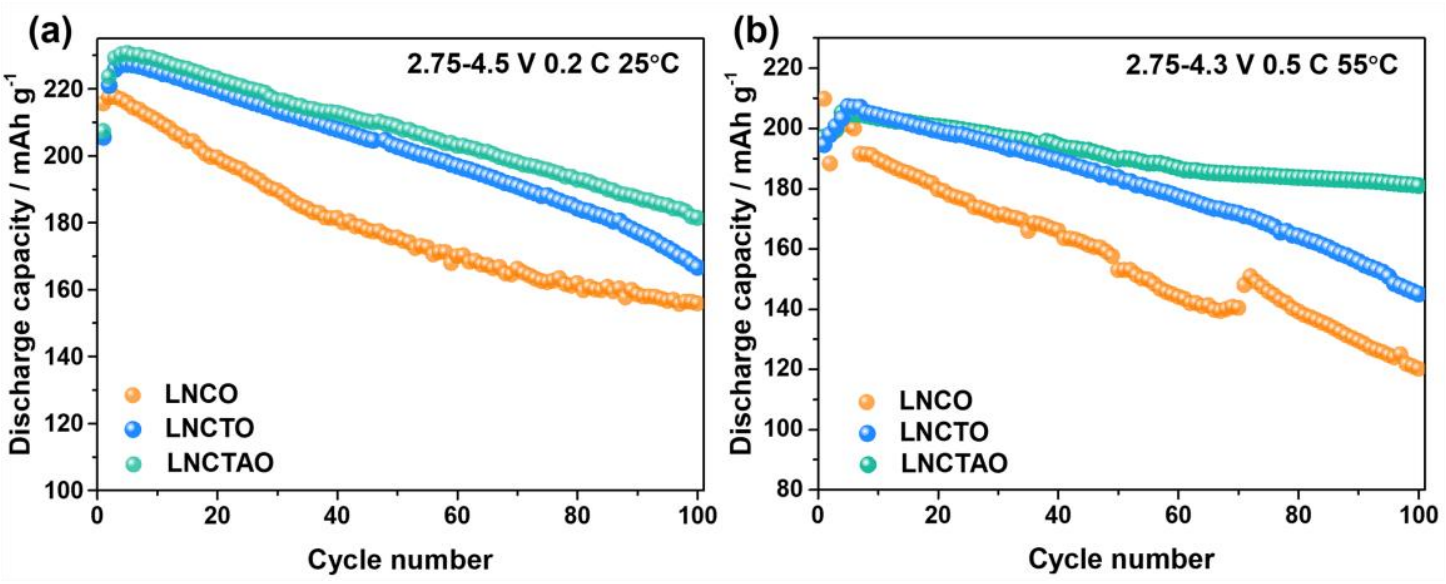

Figure S7 Electrochemical performance of LNCO, LNCTAO, and LNCTO. (a) Cycling performance at $0.2 \mathrm{C}$ rate and $25 \square$ within $2.75-4.5 \mathrm{~V}$, (b) Cycling performance at $0.5 \mathrm{C}$ rate and $55 \square$ within $2.75-4.3 \mathrm{~V}$ 

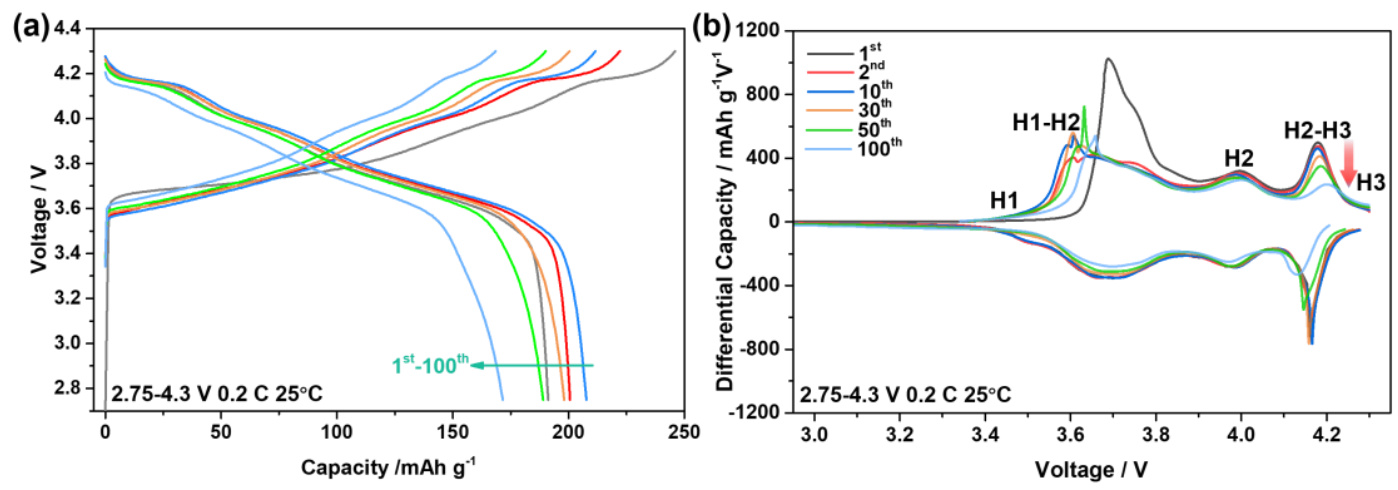

Figure S8 (a) Charge/discharge curves of LNCTO from the 1st cycle to 100th cycle at $0.2 \mathrm{C}$ and $25 \square$ within $2.75-4.3 \mathrm{~V}$, (b) The corresponding di $\square$ erential capacity vs. voltage curves of Fig. S6a. 
Table S3. The various peak ratios of the SXAS tests.

\begin{tabular}{lcc}
\hline & & \\
& & $\mathrm{Ni} / \mathrm{L}_{3 \text { high }} / \mathrm{L}_{3 l o w}$ \\
Samples & & \\
\hline & Pristine & 0.7604 \\
& 50 cycled & 0.3983 \\
LNCTAO & Pristine & 0.5458 \\
& 50 cycled & 0.5319 \\
LNCTO & Pristine & 0.5890 \\
& 50 cycled & 0.3706 \\
\hline
\end{tabular}




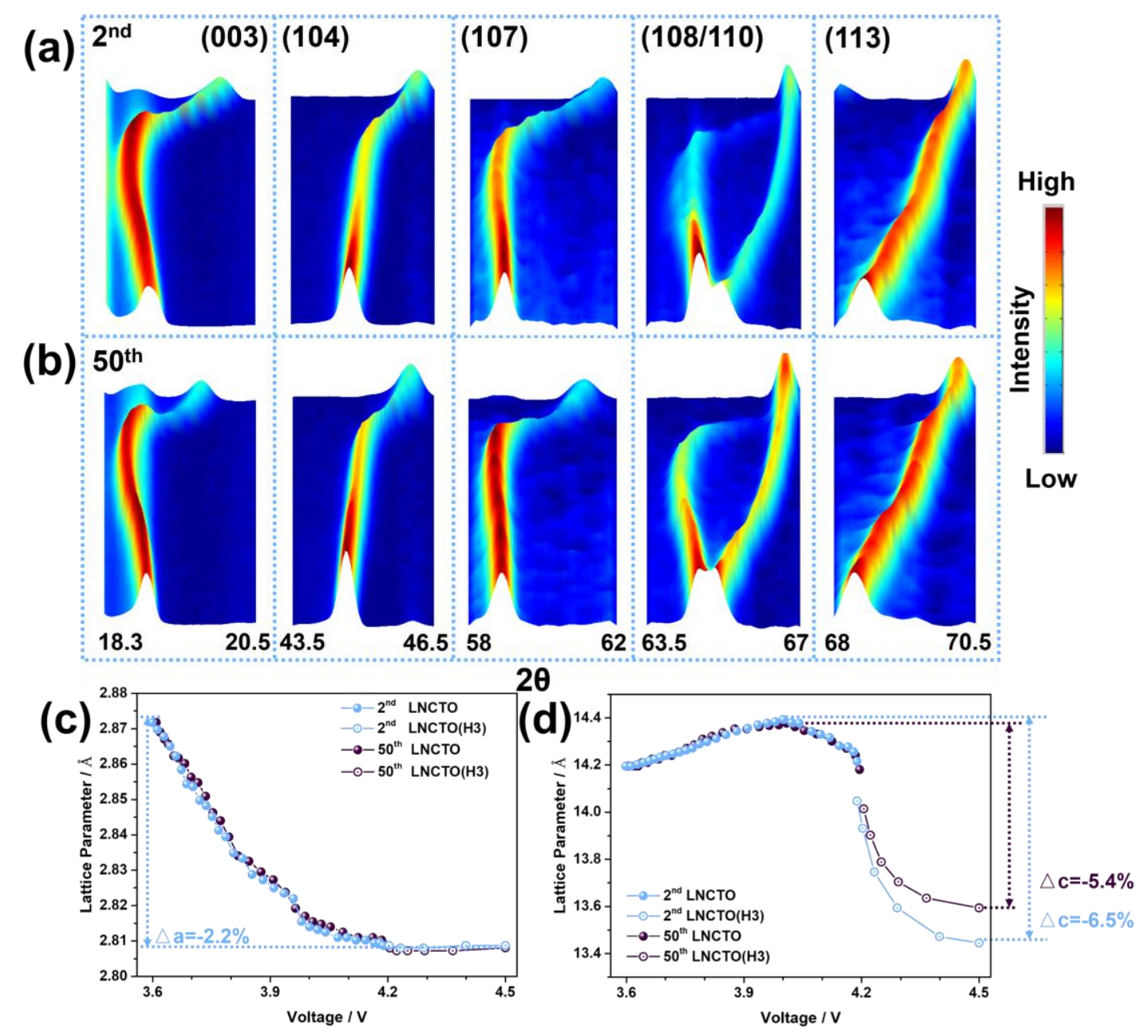

Figure S9 In situ XRD of LNCTO charged at $0.1 \mathrm{C}$ charged from $2.75 \mathrm{~V}$ to $4.5 \mathrm{~V}$ during the $2^{\text {nd }}$ and $50^{\text {th }}$ charge cycle. $(a, b)$ Contour plot of the diffraction patterns from (003) to (113) peaks and $(c, d)$ the corresponding evolution of the lattice parameters a and $c$. 


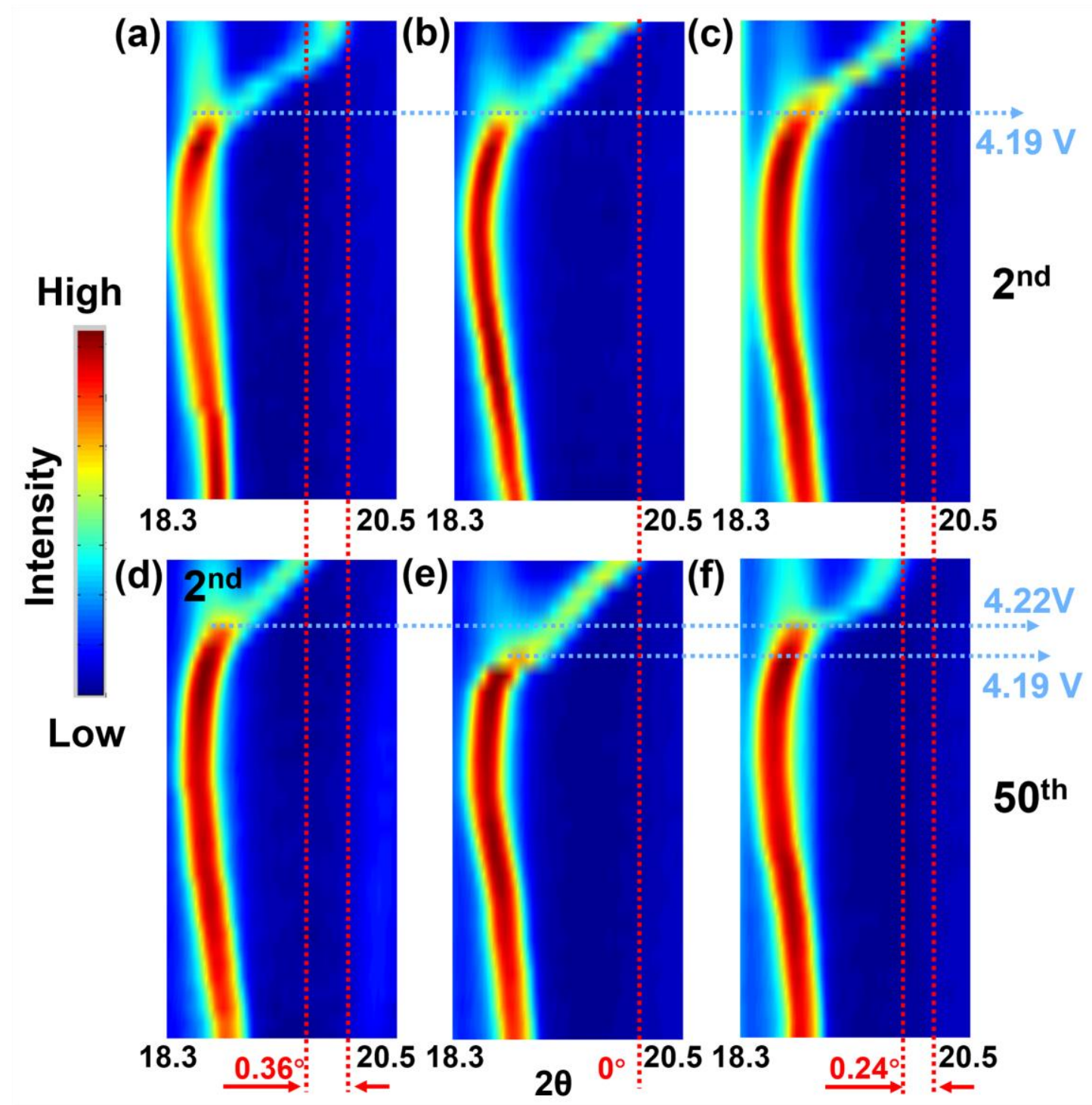

Figure S10 In situ XRD contour plot of the diffraction patterns (003) peak of $\operatorname{LNCO}(\mathrm{a}, \mathrm{d})$, $\operatorname{LNCTAO}(b, e)$ and $\operatorname{LNCTO}(\mathrm{c}, \mathrm{f})$ charged at $0.1 \mathrm{C}$ charged from $2.75 \mathrm{~V}$ to $4.5 \mathrm{~V}$ during the $2^{\text {nd }}$ and $50^{\text {th }}$ charge cycle. 


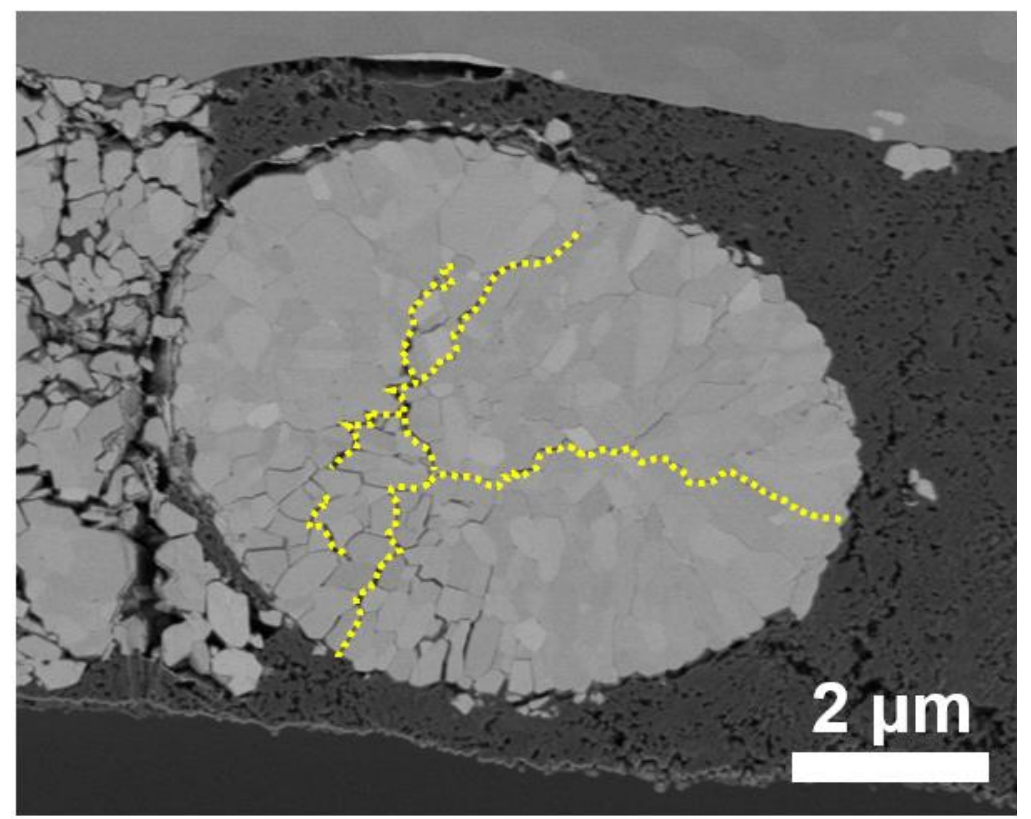

Figure S11 The cross-sectional SEM images of LNCTO after 50 cycles. 

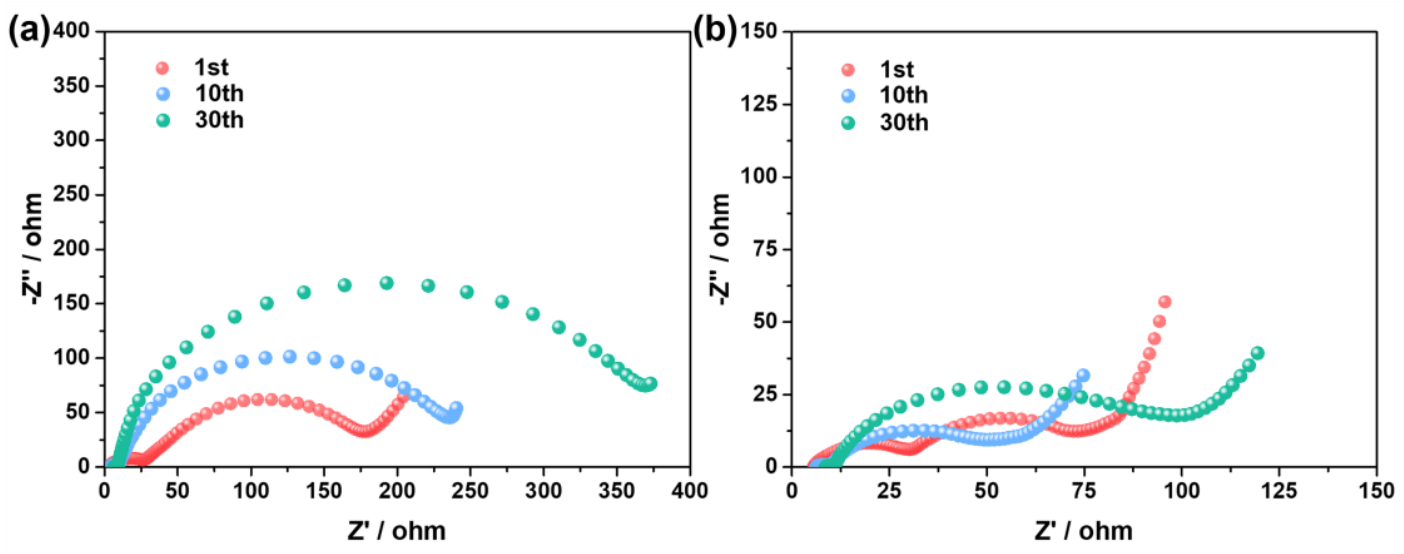

(c)

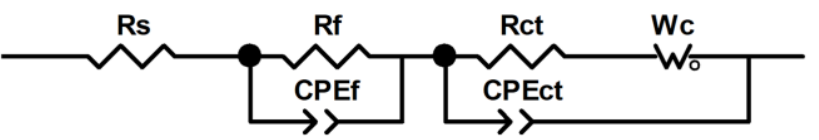

Figure S12 Nyquist plots for LNCO (a), and for LNCTAO (b) at $4.3 \mathrm{~V}$ potential, (c) Equivalent circuit for the electrochemical impedance of all the samples. The frequency range is from $10^{5}$ to $10^{-3} \mathrm{~Hz}$. 

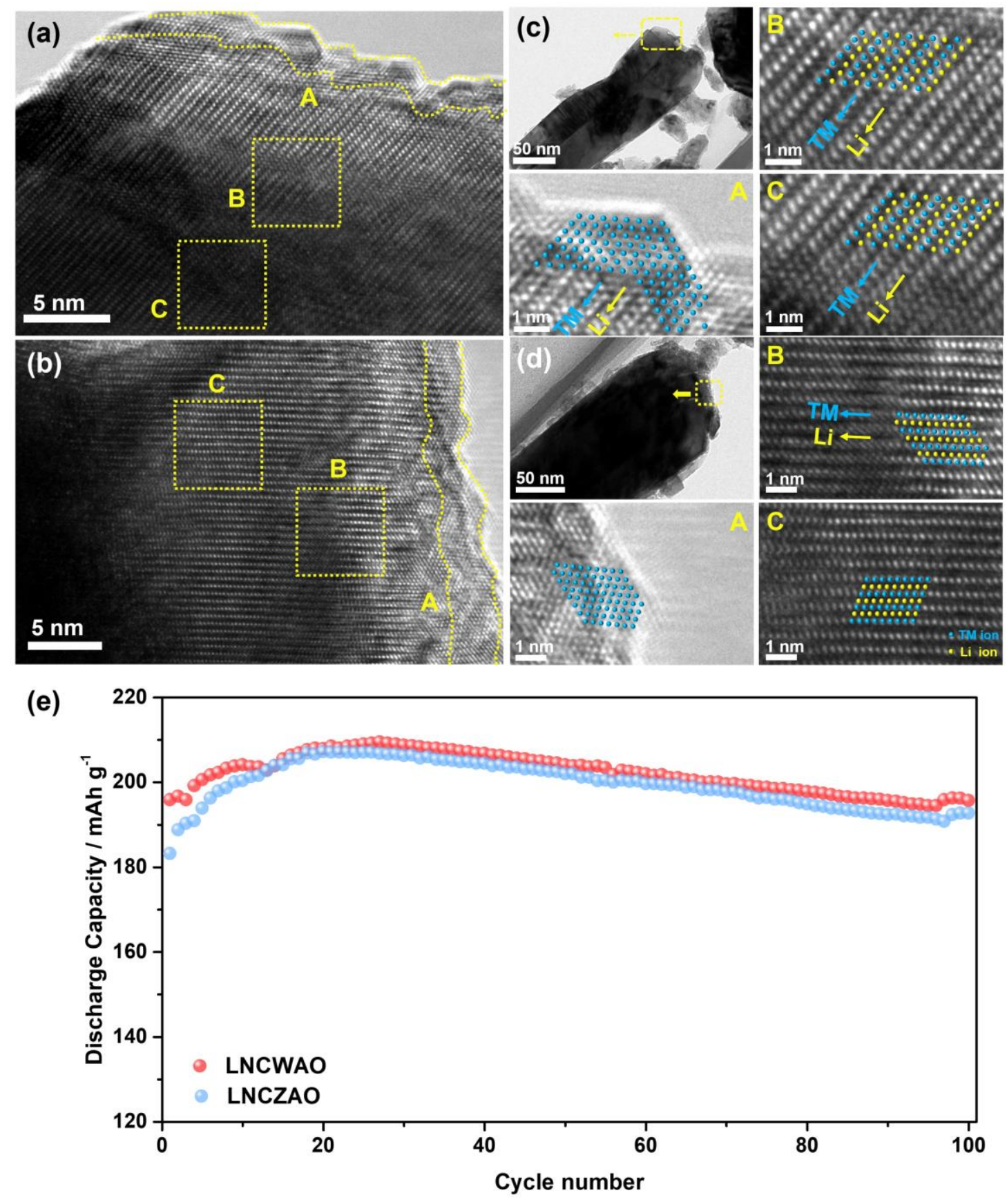

Figure S13 TEM images of the LNCWAO (a) and LNCZAO (b). The corresponding Lowmagnification TEM images of LNCWAO (c) and LNCZAO (d). High-magnification TEM images and FFT images of the marked regions A, B and C (marked by yellow dash lines) are shown at right of the image, respectively. (e) the cycling performance of LNCWAO and LNCZAO at $0.2 \mathrm{C}\left(1 \mathrm{C}=190 \mathrm{~mA} \mathrm{~g}^{-1}\right)$ rate and $25 \square$ within $2.75-4.3 \mathrm{~V}$. 